\title{
HOME-BASED REINFORCEMENT AND THE MODIFICATION OF PRE-DELINQUENTS' CLASSROOM BEHAVIOR ${ }^{1}$
}

\author{
Jon S. Bailey, Montrose M. Wolf, and Elery L. Phillips \\ BUREAU OF CHILD RESEARCH AND DEPARTMENT OF HUMAN DEVELOPMENT \\ UNIVERSITY OF KANSAS
}

\begin{abstract}
In Exp. I, five pre-delinquents from Achievement Place attended a special summer school math class where study behavior and rule violations were measured daily for each boy. The boys were required to take a "report card" for the teacher to mark. The teacher simply marked yes or no whether a boy had "studied the whole period" and "obeyed the class rules." All yeses earned privileges in the home that day but a no lost all the privileges. Using a reversal design, it was shown that privileges dispensed remotely could significantly improve classroom performance. In Exp. II and III, home-based reinforcement was also shown to be effective in improving the study behavior of two youths in public school classrooms. In addition, data from Exp. III suggest that the daily feedback and reinforcement may be faded without much loss in study behavior. Home-based reinforcement was demonstrated to be a very effective and practical classroom behavior modification technique.
\end{abstract}

The analysis and modification of children's behavior in the classroom has become an active area of investigation in recent years. Many studies have shown that disruptive behavior can be reduced, study behavior increased, and grades improved by the relatively simple application of behavior modification techniques. Most of the techniques developed have involved the teacher as the key element in the modification of student behavior (Hall, Lund, Jackson, 1968; Thomas, Becker, and Armstrong, 1968; Madsen, Becker, and Thomas, 1968). That is, typically a teacher has been taught how to deliver social reinforcers more efficiently, to ignore inappropriate behavior, and how to provide other consequences to improve the academic behavior of her pu-

\footnotetext{
${ }^{1}$ This study is based upon a dissertation submitted by the senior author to the Department of Human Development in partial fulfillment of the requirements for the Ph.D. degree. The research was supported by PHS Training Grant HD 00183 from NICHD, Grant HD 03144 from NICHD, and Grant MH 16609-01 from the NIMH Center for Studies of Crime and Delinquency to the Bureau of Child Research and the Department of Human Development, University of Kansas. The authors wish to thank Mr. Kenneth Fisher, Principal, and his staff at Central Junior High, and especially Mrs. Johnson and Mr. Corbett, teachers, for their help and full cooperation. Reprints may be obtained from Jon Bailey, Psychology Department, Florida State University, Tallahassee, Florida 32306, or from Mont Wolf, Department of Human Development, University of Kansas, Lawrence, Kansas 66044.
}

pils (O'Leary, Becker, Evans and Saudargas, 1969).

In some cases, however, it may be impractical or impossible to train teachers to record student behavior, to devise appropriate consequences, and to arrange precise contingencies to change the students' behavior. In other cases (e.g., with severe behavior problems or with many delinquents), the students may simply not be affected by reinforcers normally available to a classroom teacher. In such cases it may be desirable to seek reinforcers elsewhere. A child's home may be the source of a great deal of reinforcement and several studies (Cantrell, Cantrell, Huddleston, and Woolridge, 1969; McKenzie, Clark, Wolf, Kothera, and Benson, 1968; Thorne, Tharp, and Wetzel, 1967) have shown that it may be feasible to arrange for the parents to deliver reinforcers for behavior occurring in other settings, the school, for example. The present research sought to develop and evaluate such a system for the remote reinforcement of classroom behavior of the pre-delinquents at Achievement Place, using reinforcers delivered at home.

Achievement Place, in Lawrence, Kansas, is a home-style treatment program for pre-delinquents (youths under 16 who have committed a series of serious crimes and who have not yet been sent to the state industrial school). In addition, Achievement Place is established on a token economy (Ayllon and Azrin, 1968). That is, the boys earn points by engaging in 
social, self-care, and academic behaviors, that are seen as necessary for their eventual rehabilitation. These points are then exchanged for various privileges available at Achievement Place such as permission to watch T.V., go outside, or ride their bikes, or the points may be exchanged for snacks or allowance or certain preferred positions in the home (e.g., the "manager" position).

In addition to being in sufficient trouble in the community to warrant processing through the Juvenile Court, the boys who come to Achievement Place are invariably reported to be causing problems in the public schools. These may range from being habitually tardy or truant, to cutting classes, or to committing acts of aggression in class. Once a boy comes to Achievement Place these major problems usually diminish greatly, but typically the boys still do not perform well in class. They are frequently reported not to pay attention to the teacher, follow instructions, or complete assignments. Much of their time is spent in talking to others, looking out the windows, and playing with objects they bring to class. They may be one to two grades behind their peers and are almost always on the borderline of failure, rarely making grades above a $D$.

Previous research (Phillips, 1968) has demonstrated that many different behaviors can be modified through the use of contingent points delivered and backed up at Achievement Place. Aggressive statements have been eliminated, tardiness reduced, room cleanliness improved, and homework accomplished when points were given and taken away contingent on the occurrence or nonoccurrence of a particular behavior. Achievement Place is an ideal setting in which to analyze the effects of reinforcement delivered at home, since many of the problems usually associated with such a task have been overcome. Effective reinforcers have already been discovered and extensively evaluated, their delivery can be objectified and verified by means of the token system, and since the house-parents are experienced experimenters, there is little problem with inconsistency at Achievement Place.

\section{EXPERIMENT I}

\section{Subjects}

Five boys, aged 11 to 15 yrs., who had been declared dependent-neglected and assigned by the Juvenile Court to Achievement Place served as subjects. Three had been labelled "school behavior problems" by their teachers, two were enrolled in special education classes, and all were considered poor academically ( i.e., grades of $\mathrm{D}$ to $\mathrm{F}$ ). One boy was reported to have been sent to the principal's office for disrupting class so often during the previous school year, that he was suspended twice and failed the grade as a result. The two other behavior problems were described as "uncontrollable" by many teachers in the public school. One reportedly assaulted not only the students but a teacher as well. The other seemed quite verbal and teachers reported that he frequently talked back to the teachers and disrupted the classes in other non-physical ways. The two boys in special education were reported to spend most of their time "daydreaming", looking out the windows, and playing with objects brought to class.

\section{Setting}

The experiment was carried out during the summer in a special classroom setting at the University of Kansas. The room was equipped much like a regular schoolroom with desks, a blackboard, pictures on the walls, a pencil sharpener, and waste basket. The boys sat facing an observation booth (with one-way mirrors), the blackboard and the teacher's desk. The teacher was instructed to be pleasant but not to praise or disapprove of any behavior for the duration of the study.

The first day of the summer school, the teacher introduced herself and chatted briefly with the boys about the class they would be attending. She then listed the following class rules on the blackboard: (1) Do not leave seat without permission. (2) Do not talk without permission. (3) Do not look out the windows. (4) Do not tilt desks. (5) Do not make noise. (6) Do not disturb others. She then added at the bottom: "Remember, you should work the whole period!" (The rules were compiled from those suggested by the boys' teachers in the public schools.) Next, the youths were each given math workbooks ${ }^{2}$ and told that they were to work in them during each class meeting and that if they had any questions on the

${ }^{2}$ Durell, T., Hagaman, A., and Smith, J. Arithmetic for today (Books 3-II). New York: Charles E. Merrill, Inc., 1960. 
problems they could raise their hands to ask for help and the teacher would call them up to the desk. The class differed from most in that there were no general class discussions or lectures by the teacher. Two half-hour class sessions, separated by a 10-min break, were held each morning five days a week.

\section{Observation Technique}

Two experienced observers were stationed in the observation booth, each with a stopwatch, clipboard, and data sheet marked off in boxes for 10-sec interval observations (Hall et al., 1968). One observer was given a definition of "rule violations" and scored all such violations for all the boys (the boys sat close enough together and the observer's vantage point was such that all could be easily seen). The second observer was given a definition of "study behavior" and also scored all the boys for this category. Observations began when the teacher said: "Okay, I guess it is time to begin" (or the equivalent) and ceased when she similarly indicated that the 30 -min session was over.

Inter-observer agreement was analyzed by having a third observer periodically make a simultaneous but independent observation record. Agreement was measured by comparing the two records for agreement interval by interval and the per cent agreement was calculated (number of agreements $\times 100 \div$ the total number of intervals observed).

\section{Behavior Definitions}

An instance of rule violation by a subject was scored for any 10-sec interval for any boy who violated any of the rules listed on the blackboard that included the following behavioral definitions:

Talking without permission: any vocalization audible in the booth without the subject's being called on by the teacher.

Making noise: tapping pencils, hands, or feet loud enough to be heard in the booth, includes noise made by dropping materials if it can be heard in the booth.

Out of seat: subject must break all contact with his assigned seat without permission, i.e., no part of the body touching any part of the chair or desk top.

Disturbing others: touching another student (directly or indirectly) or article that he is holding or is in possession of; gesturing or posturing in the direction of another student sufficient to make him look up from his work.

Desk tilting: lifting any two legs of desk off floor while still seated in it.

Looking out window: head and eyes oriented in direction of window (which was behind the boys and therefore required them to turn at least $90^{\circ}$ in their seats).

Study behavior was defined in terms of ontask behavior, i.e., head and eyes oriented at workbook materials. Any other behavior (e.g., looking out the window or at the clock, etc.) was scored as non-study except: (1) when a student had permission to be away from the materials or, (2) if no student was at the teacher's desk, hand raised and head and eyes oriented toward the teacher was scored as study behavior. Study behavior had to occur for a full 10-sec interval to be scored as study; any interruption resulted in the interval being marked as non-study.

\section{Experimental Conditions}

Baseline. No observational data were taken the first day of class described above because the students were not instructed to work in the workbooks and the session was merely introductory in nature. From the second day forward, however, the two measures, study and rule violation behavior, were taken for each boy for every 30 -min period. During the baseline the youths simply came to the classroom each morning and worked in the workbooks. No scheduled consequences occurred for either studying or doing math problems during the periods, although the teacher graded their work at the end of each day. The number of problems worked and the number correct were recorded each day for each boy.

"Yes" only condition. The purpose of the first condition was to determine the effects of back-up reinforcement but non-differential feedback to the youths. The boys were required by the house-parents of Achievement Place to carry a daily report card ( 4 by 5 in. in size). The card was designed in such a way that the teacher could check yes or no for "obeyed the classroom rules" and "studied the whole period" for both math periods. The boys were told that if they received all yeses they would earn sufficient points (1000) to purchase three significant privileges for the remainder of the day. These were snacks, T.V., and permission to go outdoors. If they received 
even one no they were told that they would lose all these privileges and that they would have to do extra chores (the equivalent of 6000 points) if they wanted to earn them back.

The youths brought the cards to school and gave them to the teacher at the beginning of the first period. At the end of the second period, the teacher would usher the youths out to the waiting car and return to her desk. Since we wanted to measure the effects of nondifferential feedback, the teacher was instructed to mark all categories yes for all boys regardless of whether she thought they had "studied the whole period" or "obeyed the classroom rules". After marking the cards and signing them, she took the cards out to the youths. The time required from their leaving the class until they got their marked cards, averaged about a minute and a half.

The house-parents acknowledged the checkmarked cards and dispensed the privileges matter-of-factly to the boys.

"Yes" and "no" condition. In the second condition, the effects of the teacher discriminating between "good" and "bad" class behavior were analyzed. To insure precision in marking the cards, the decision to mark yes or no was based on the data kept by the observers in the booth. A cut-off of $10 \%$ was used for rule violations and $90 \%$ for study behavior. That is, if a boy had more than $10 \%$ of the intervals for either period marked as rule violations he was marked no for that period; he was marked yes if he had less than $10 \%$ rule violations. Likewise, if less than $90 \%$ of the intervals were marked for study he was checked no but $90 \%$ or more resulted in a yes for that period.

The percentages for each boy were calculated as soon as each class was dismissed and the teacher was accordingly instructed, through the one-way mirror, how to mark the cards. She then took the cards to the youths as before. Privileges were granted or withdrawn at Achievement Place based on the markings of the cards.

No back-up reinforcement condition. In order to assess the effects of back-up reinforcers in the home, the next condition involved the removal of these back-ups. The boys were told by a house-parent one morning before they left for school, that they did not have to receive all yeses to earn the privileges. Rather, they were told that they were granted them free as of that time. They were still required to take the cards for the teacher to mark, however. The teacher still assigned the marks based on the observation data to keep this form of feedback to the boys constant.

"Yes" and "no" condition. After several days of the previous condition, the boys were instructed before they left for class that they would once again have to earn the privileges by getting marked all yeses on the daily cards. Apart from this initial instruction, this condition was identical to the first yes and no condition.

\section{RESULTS}

A total of 13 reliability checks were made throughout the study. Six reliability checks on the study behavior definition were taken throughout the experiment. The range of observer agreement was from $75 \%$ to $96 \%$ with a mean of $87 \%$. Seven checks were made on the occurrences of rule violations with agreements ranging from $79 \%$ to $99 \%$ and a mean of $89 \%$.

Data for all five boys as a group are shown in Fig. 1. The first two and a half days of the summer school the boys were perfect students; they studied more than $85 \%$ of the intervals and committed rule violations much less than $10 \%$ of the time. A steady deterioration in study and an increase in rule violations occurred after that, however, and on the last day of the baseline, they were studying less than $35 \%$ of the intervals and rule violations occurred in more than $60 \%$ of the intervals.

When the boys began taking the daily report card, study behavior improved and rule violations dropped drastically. But, apparently since there were no differential consequences for good classroom behavior, study again fell, this time to less than $30 \%$ of the intervals and rule violations rose more than $25 \%$ by the end of the two-week period.

On the first day that the criteria for both behaviors were employed, all youths lost the privileges. On the second day, a great improvement in study was observed and by the third day three of five boys received all yeses by meeting the criterion for both behaviors. For the rest of the two weeks, study remained close to $95 \%$ and rule violations occurred in less than $5 \%$ of the intervals.

On the first day of the no-backup reinforcement condition, study behavior dropped to less than $75 \%$ and in three days fell to almost 


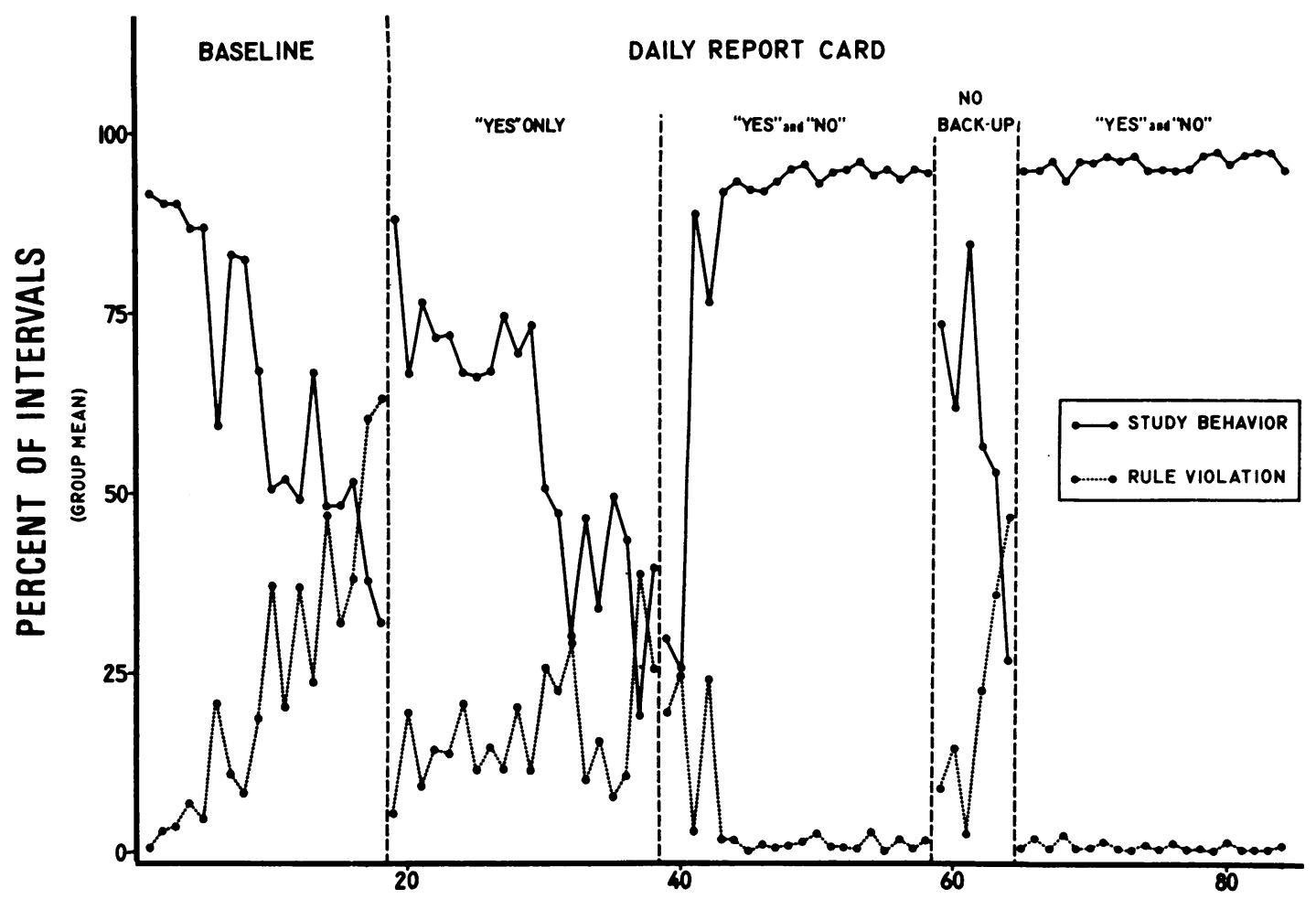

\section{SESSIONS}

Fig. 1. Mean per cent of intervals of study and rule violations for all five subjects under each treatment condition.

$25 \%$. Rule violations during the same time climbed to a high of $46 \%$.

Reinstatement of the back-up reinforcement resulted in an immediate improvement in study above the criterion of $90 \%$ and rule violations dropped to about $2 \%$, well below the $10 \%$ criterion. This almost perfect performance lasted throughout the two weeks of this condition, including the final day of class.

Graphs of individual student data for all five conditions are shown in Fig. 2 and 3. It may be seen that the individual records are well represented by the group means in Fig. 1 .

Figure 4 shows the number of problems worked and the number correct under each condition for all the boys. During baseline conditions, the number worked dropped steadily, from 600 to fewer than 300 , throughout the condition. The first day that they began taking the cards, the number worked increased almost to the level seen on the first day of baseline, but over the course of nine days it dropped to fewer than 300 per day for all the boys to- gether. On the first day that the youths lost their privileges for not studying according to the criterion, they also did very few problems (fewer than 100). This number increased to a high of 700 on the sixth day of the "yes" and "no" condition and then appeared to decline slightly thereafter. When the back-up reinforcement was removed, the number of problems worked dropped to fewer than 100 once more and a return to the differential consequences was followed by an increase in the number worked to over 400 , where it remained stable for the two final weeks of the experiment. There thus appeared to be a correlation between the number of problems worked (i.e., output) and the definition of study behavior used by the observers. In fact, the Pearson correlation coefficient was +0.64 for this relationship.

It may also be noted that, in general, the number of problems worked correctly also correlated fairly well with each of the different conditions. The increasing distance between 

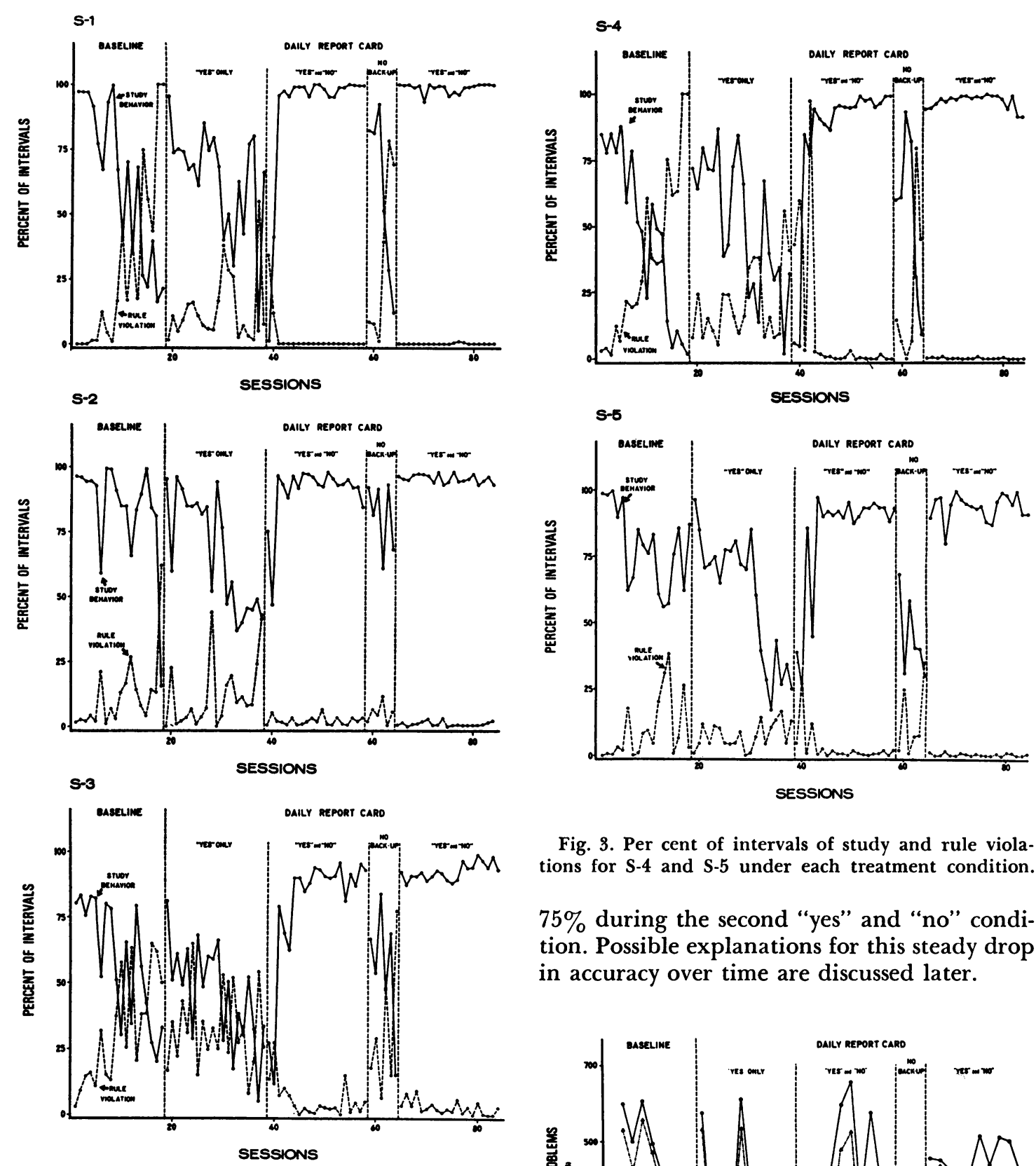

Fig. 3. Per cent of intervals of study and rule violations for S-4 and S-5 under each treatment condition.

$75 \%$ during the second "yes" and "no" condition. Possible explanations for this steady drop in accuracy over time are discussed later.

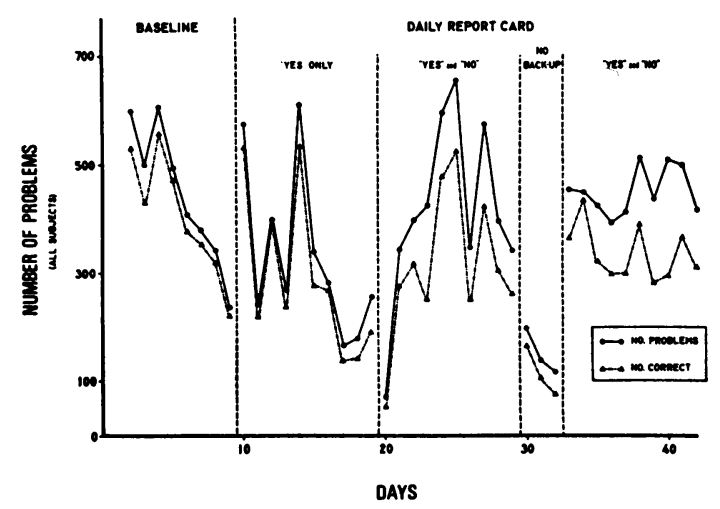

Fig. 2. Per cent of intervals of study and rule violations for S-1, S-2, and S-3 under each treatment condition.

the two lines of Fig. 3 indicates that the boys were making more and more errors over time. They correctly worked $92 \%$ of the problems during baseline, $86 \%$ during the yes only condition, $75 \%$ during the first "yes" and "no" condition, $73 \%$ during the no back-up, and

Fig. 4. Total number of problems worked and problems correct for all subjects under all treatment conditions. 


\section{EXPERIMENT II}

The first study indicated that under conditions where standardization and control over subject matter and instructional control over the teacher were gained, clear improvements in classroom behavior could be achieved with home-based reinforcement. A second question then arose. Could such results also be obtained in a public school setting where assignments and routines change from day to day and where a teacher may or may not effectively discriminate between appropriate and inappropriate class behavior? Experiment II was carried out to examine this question.

\section{Subject}

A 15-yr-old boy from Achievement Place, who had a long history of classroom disruptiveness and inattentiveness served as the subject. His math teacher requested help with him because he did not seem to be "applying himself". She described him as constantly talking out and disturbing others.

\section{Procedures}

Observation and recording. An observer took data from the back of the class using a 10-sec time-sample technique. That is, at the end of each 10-sec interval she would look at the subject and score his behavior. To help insure against possible observer bias, the observer was never told the purpose of the experiment or when a change in conditions was to take place. In addition, the manipulations were such that there were no cues provided to the observer as to conditions in effect. Reliability of the measurement procedures was assessed with a second observer and was calculated as in Exp. I.

As in Exp. I, study behavior was defined as head and eyes oriented toward assigned materials. In case of a group discussion, study was counted if the youth was speaking (with permission), or looking at the speaker or toward the discussion materials. In addition, any contact with the teacher (with permission) or behavior permitted by the teacher was counted as study behavior. Any behaviors other than those listed above were scored as non-study.

Baseline. During baseline, study behavior was recorded for each math period. No feedback was given to the teacher and the subject was not aware that he was being observed.
Daily report card. Under this condition, the subject took a daily report card for the teacher to check. Several categories, suggested by the teacher, were to be marked yes or no. These were: acceptable use of class time; assignment completed on time: homework assignment is or better quality; quiz or exam is

or better; (a grade the subject could obtain was placed in the blank) and overall behavior: good.

The youth brought the cards home and if he earned all yeses he received the major privileges, snacks, T.V. and permission to go outdoors. Even one no resulted in loss of these and they had to be made up through extra chores as in Exp. I.

No card. In this condition, the subject was told he did not have to take the card and that he was granted the privileges free. The teacher was not informed in advance of this change in conditions.

Daily report card. The youth was once again required to take the card and to earn the above mentioned privileges.

\section{Results}

Five reliability checks were taken during the study. Agreement ranged from $79 \%$ to $99 \%$ with a mean of $91 \%$.

Baseline was carried out for nine days. Figure 5 shows that study behavior ranged from $3 \%$ to $45 \%$ during this time. When he began taking the card, the subject's study behavior immediately rose to over $95 \%$ and remained high for six days. He was never marked no by the teacher during this condition.

When the youth no longer had to take the card, his study dropped drastically to less than

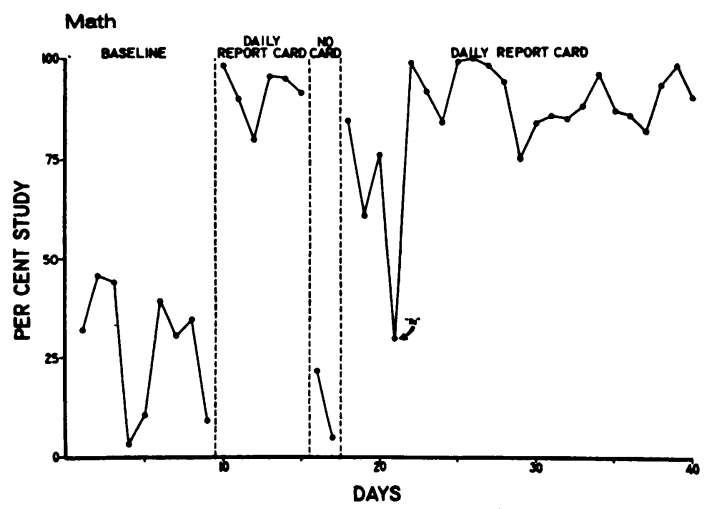

Fig. 5. Per cent of time spent in study by one student in a public school math class under all conditions. 
$25 \%$ on the first day of the reversal condition. On the second day, study occurred less than $10 \%$ of the time and the youth reportedly was involved in a scuffle in class in which two other boys were sent to the office. The teacher told the observer, after the class, that our subject would have been sent too, except that she knew he was involved in some kind of study and she did not want to "mess it up".

The next day he began taking the card again and study again jumped, this time to above $80 \%$. Study behavior dropped for the next three days as the subject appeared to "test" the teacher. On the fourth day of this condition, the teacher marked the subject no for the first time for not studying and paying attention (see arrow in Fig. 5). The next day, study occurred almost $100 \%$ of the time and remained high for the rest of the school term without the subject's being marked no for his class behavior. (He was, occassionally marked for not doing an assignment or not meeting criterion on a quiz or exam, however.)

\section{EXPERIMENT III}

One further question involving the use of the daily report card system is whether a youth can be "weaned" from the immediate feedback contingencies to a more "normal" form of these. That is, a more normal and practical system is one in which the feedback and contingencies are more intermittent and where some other form of "natural consequence" must bridge the gap between behavior and privilege earned. This question was addressed in Exp. III.

\section{Subject}

The subject again was a youth from Achievement Place. He too had a reputation for talking out and disturbing others in class and was clescribed as spending the majority of his time trying to ignore the content of his courses. His science teacher reported that he was inattentive, for the most part, and that he would do well to take better notes in class to complete his assignments.

\section{Procedures}

Observation and recording. A trained observer sat at the back of the class and recorded two classes of behavior, study behavior and rule violations, in 10 -sec intervals. Study be- havior was defined as head oriented in the direction of the speaker or materials used by the speaker. Behaviors other than these, including laying his head on desk, looking out the window, playing with pencils and yawning or stretching were scored as non-study. Study had to occur for the full 10-sec of an interval in order to be counted; any break in study behavior during the interval resulted in it being marked as non-study.

Any behaviors contrary to the teacher's class rules were considered rule violations. These were ascertained after several days of observation and in consultation with the teacher. The class rules were: no talking out, no getting out of seat, no making noise, no dropping or throwing of materials, and no waving of the arms. Any intervals in which any of these behaviors occurred were scored as rule violations.

Baseline. For four days, the observer attended each science class and recorded study behavior for the full period. She also made brief notes as to other behaviors that might be considered rule violations. The teacher was requested to continue his normal routine and, as much as possible, simply to ignore the observer.

Daily report card. The subject carried the card to school each day and at the end of the class took it up to the teacher to mark yes or no in the categories: paid attention and studied the whole period; obeyed the classroom rules; completed homework on time and earned at least ___ ; earned at least ___ on quiz or exam (grades the youth could make if he tried were inserted in the blanks). A card marked all yeses earned 1000 points for the day at Achievement Place and could be exchanged for the major privileges listed in Exp. I and II.

No card. For three days the youth was told he did not have to take the daily card to school and that the privileges were granted free for those days.

Daily report card. The subject again took the daily report card and earned 1000 points by getting marked all yeses.

Fading card. For the remainder of the semester, the youth carried the report card only on Tuesday and Friday of each week. The teacher was instructed that each card could be marked for the days in between. That is, an infraction on Monday or Tuesday could be marked on the Tuesday card and likewise an infraction on Wednesday, Thursday, or Friday 
could be marked on the Friday card. On days that a card was not taken, no points were earned for school but the points accumulated until the card was taken. For example, all yeses on the Tuesday card earned 2000 points and on Friday earned 3000 points. A "no" for either lost the same number of points.

\section{RESULTS}

During baseline, the subject's study ranged from $40 \%$ to about $60 \%$ of the intervals scored, as shown in Fig. 6. No data on rule violations were taken during this condition. When the subject began taking the card, study improved to $97 \%$ on the first day and averaged above $90 \%$ for the three weeks that he took the card. Rule violations occurred in about $1 \%$ of the intervals in this condition.

Under the condition where the subject was instructed not to take the card, study dropped immediately back to baseline levels but rule violations did not appear to increase in frequency. When he was again required to take the card, study improved to the previous high levels and occurred over $95 \%$ of the intervals for the last three days.
On two days, the regular teacher was absent and a substitute took charge of the class. On these days, the subject had the teacher write a note on a separate piece of paper indicating that the regular teacher was not present. The houseparent accepted these notes as equivalent to all yeses even though the daily card categories had not been marked or even seen by the substitute. As shown in Fig. 6, study dropped to very low levels during this time with a substitute teacher $(39 \%$ on the second day) and rule violations rose to an all time high of $34 \%$.

After the regular teacher returned, the daily card was in effect for almost one month. Study behavior dropped below $85 \%$ on only one occasion and averaged $90 \%$ of the intervals observed. Very few rule violations occurred during this time with the most being $2 \%$ on one day.

For the last five weeks of the school term, the fading card was taken twice a week. Study behavior in general remained fairly high but fell below $85 \%$ on six occasions. The average for the five-week period was $87 \%$, only a little less than that under the daily card condition.

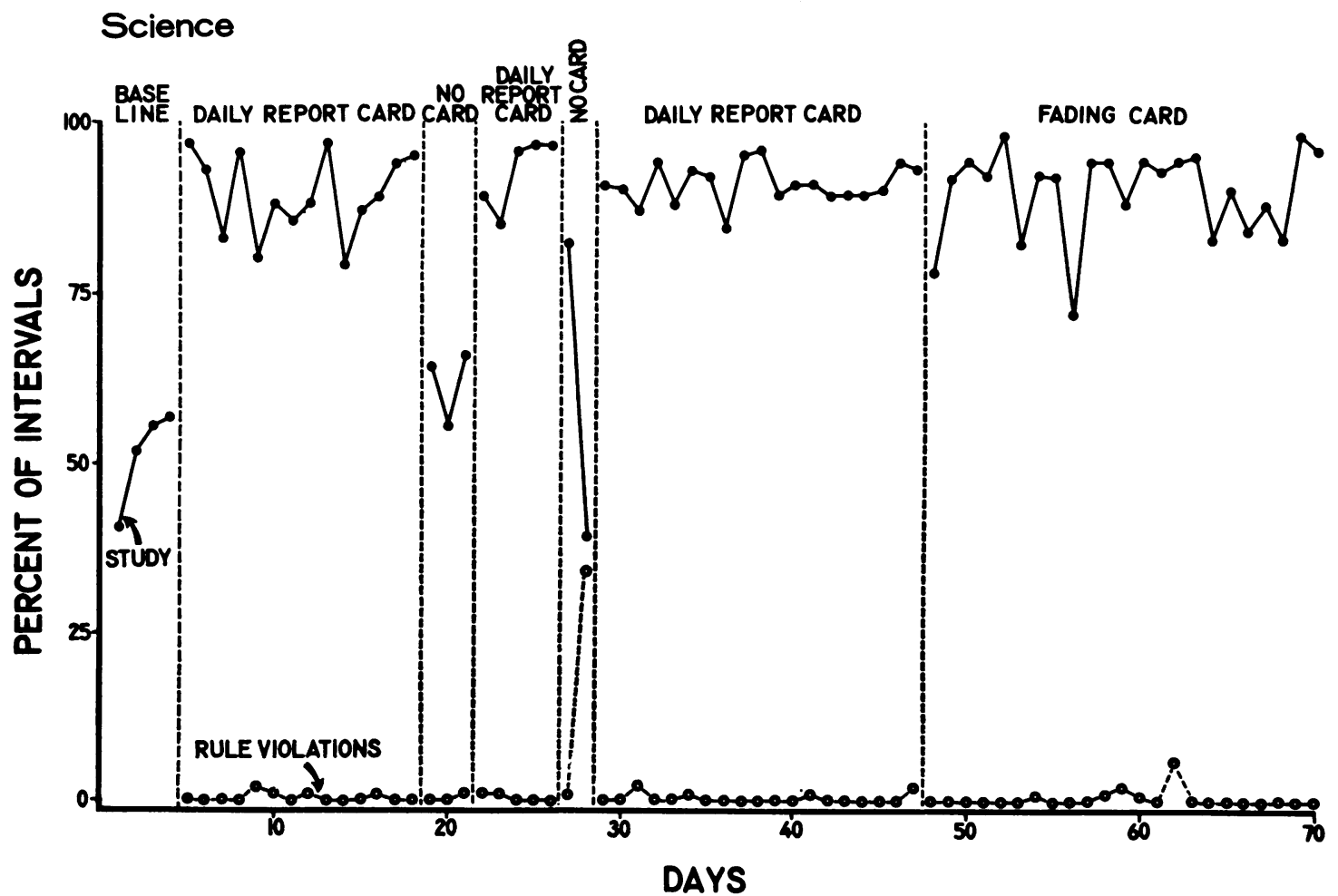

Fig. 6. Per cent of intervals scored as study and rule violations for one student in a science class under all conditions. 
Compared with the daily card, the fading card seemed to produce much more variability in study behavior. Rule violations also generally remained quite low, the highest being $6 \%$ on one day during the fading condition.

\section{DISCUSSION}

The consequences delivered at home clearly modified the school behavior of the youths at Achievement Place. The effect was demonstrated both in a special classroom setting where exact control over curriculum and teacher behavior could be achieved and in the regular public school where no control over either was possible. The data from Exp. I strongly suggest that these home-based or remotely delivered consequences depend on at least two conditions. The first is a teacher who differentiates the appropriate from the inappropriate behavior to be modified. Second, but of equal importance, is the necessity of back-up reinforcers in the home. If either is missing, it appears, behavior cannot be changed remotely.

In Exp. I, output (in this case, number of problems worked) covaried with study behavior fairly closely. Even though there was no contingency for doing problems, they did more problems when they also "studied" more. Number of problems correct declined steadily over time, however. This may have been due to one of several factors. First, the problems became harder over the course of the summer. As the boys progressed through the workbooks, problems changed from simple division and multiplication to complex word problems, long division, decimals, and the multiplication and division of fractions. Second, there was the possibility of cumulative error. That is, if a boy missed some concepts early in the book, no remediation of his deficiency was undertaken so that if the skill was required later in the workbook, there was a greater chance that an error would occur. Finally, it may have been that the subjects were simply adapting to the scheduled consequences, i.e., study behavior rather than output. In reality, all factors probably were operating to a certain extent, with the contribution of each yet to be analyzed.

From Exp. III it appears that the report card can be faded from a daily to an intermittent basis without the gains in improved study be- ing completely lost. This research has not shown at what point in time fading could optimally be started or how far fading can be extended. In addition, it is not yet known how much or what type of reinforcement at home is necessary to maintain good school behavior. In this study, three primary privileges were earned for school, but one or two may have been sufficient. An analysis of these variables is certainly necessary and desirable and is left for future research.

These data replicate and extend other findings that delinquents' school behavior can be improved through the delivery of reinforcement. Meichenbaum, Bowers, and Ross (1968) showed that "appropriate" class behavior of institutionalized female delinquents could be greatly improved through the delivery of tokens in the classroom. The tokens were exchanged for money later in the day. Cohen, Filipczak, and Bis (1967) showed that delinquents at a federal institution would work on programmed instructional materials and other educational tasks in order to earn points exchangeable for leisure time, activities, snacks, and items out of a mail-order catalog.

In a larger sense, the demonstration that home-based reinforcement can be used effectively to improve classroom performance suggests a possible supplemental technique for teachers using contingency management systems. In cases where teacher training is impossible or impractical, home-based reinforcement may be the most attractive alternative. Studies have shown repeatedly that teacher attention (Hall et al. 1968; Thomas et al. 1968; Madsen et al. 1968), access to materials (Reynolds and Risley, 1968) free-time (Osborne 1969), good behavior games (Barrish, Saunders, and Wolf, 1969), and token systems (O'Leary and Becker, 1967; O'Leary et al. 1969; Wolf,, Giles, and Hall, 1968) can be used to establish and maintain appropriate clasroom behavior and to improve learning.

The practical application of social reinforcement and token reinforcement procedures has some drawbacks. The procedures require some (perhaps extensive) training of the teacher. Typically, teachers must learn to attend regularly to and praise the good behavior of their students while at the same time trying to ignore disruptive or non-study behavior (Madsen and Madsen, 1970). This difficult task may require a trained observer to cue the teacher in 
addition to feedback and consultation with a professionally trained person. Schools operating on already slim budgets may not be able to afford the expense of these extra personnel. Token systems may be difficult for a teacher to carry out without help and may also require funds that are not available. In other cases, school rules may prevent the use of free-time, games, or other activities as reinforcers in a classroom. In addition, these procedures appear appropriate where a whole class is causing problems. A teacher faced with only one or two unruly or disruptive children may be reluctant to develop procedures involving the whole class.

A system of home-based reinforcement that does not require the teacher to learn new skills, to invent and arrange consequences, or establish token economies and which, furthermore, takes very little of her time would probably be quickly adopted by teachers; but there are obvious limitations. Teachers are already well trained to discriminate acceptable from non-acceptable class work and can, presumably, differentiate between disruptive and nondisruptive behavior. The link that needs to be added is the establishment of back-up reinforcers at home. Although McKenzie et al. (1968) and Cantrell et al. (1969) have shown that some parents' cooperation can be gained without great trouble, this may not generally be the case.

Many parents of delinquents care little for the academic achievements of their children or may be home so little of the time as to be unable to monitor or deliver reinforcers after school. Others may profess great interest but may simply not be consistent or systematic enough to make home-based reinforcement work. Clearly this procedure, then, requires the full cooperation of parents or guardians to dispense reinforcers at home.

Attempts to apply the procedures outlined in the present experiments will no doubt yield evidence on this point. Only when this further research is carried out will the practical implications for widespread application of the technique be known.

Behavior modifiers and researchers will also want to take care that they do not use these techniques without assuring themselves that the disruptive student's behavior is not the direct result of an overly aversive teacher or of educational materials that are ill suited to the student. To do so may make life very unpleasant for the student.

\section{REFERENCES}

Ayllon, T. and Azrin, N. The token economy. New York: Appleton-Century-Crofts, 1968.

Barrish, H., Saunders, M., and Wolf, M. Good behavior game: effects of individual contingencies for group consequences on disruptive behavior in a classroom. Journal of Applied Behavior Analysis, 1969. 2, 119-124.

Cantrell, R., Cantrell, M., Huddleston, C., and Woolridge, $\mathbf{R}$. Contingency contracting with school problems. Journal of Applied Behavior Analysis, 1969, 2, 215-220.

Cohen, H., Filipczak, J., and Bis, J. Case I: An initial study of contingencies applicable to special education. Silver Spring, Maryland: Educational Facility Press, 1967.

Hall, R., Lund, D., and Jackson, D. Effects of teacher attention on study behavior. Journal of Applied Behavior Analysis, 1968, 1, 1-12.

Madsen, C., Becker, W., and Thomas, D. Rules, praise, and ignoring: elements of elementary classroom control. Journal of Applied Behavior Analysis, 1968, 1, 139-150.

Madsen, C. and Madsen, C. Teaching/Discipline. Boston: Allyn and Bacon, 1970.

McKenzie, H., Clark, M., Wolf, M., Kothera, R., and Benson, C. Behavior modification of children with learning disabilities using grades as token reinforcers. Exceptional Children, 1968, 38, 745-752.

Meichenbaum, D., Bowers, K., and Ross, R. Modification of classroom behavior of institutionalized female adolescent offenders. Behavior Research and Therapy, 1968, 6, 343-353.

O'Leary, K. and Becker, W. Behavior modification of an adjustment class: a token reinforcement program. Exceptional Children, 1967, 33, 637-642.

O'Leary, K., Becker, W., Evans, M., and Saudargas, R. A token reinforcement program in a public school: a replication and systematic analysis. Journal of $A p$ plied Behavior Analysis, 1969, 2, 3-13.

Osborne, J. Free-time as a reinforcer in the management of classroom behavior. Journal of Applied Behavior Analysis, 1969, 2, 113-118.

Phillips, E. Achievement Place: token reinforcement procedures in a home-style rehabilitation setting for "pre-delinquent" boys. Journal of Applied Behavior Analysis, 1969, 1, 213-223.

Reynolds, N. and Risley, T. The role of social and material reinforcers in increasing talking of a disadvantaged preschool child. Journal of Applied Behavior Analysis, 1968, 1, 253-262.

Thomas, D., Becker, W., and Armstrong, M. Production and elimination of disruptive classroom behavior by systematically varying teacher's behavior. Jo irnal of Applied Behavior Analysis, 1968, 1, 35-45.

Thorne, G., Tharp, R., and Wetzel, R. Behavior moditication techniques: new tools for probation officers. Federal Probation, June, 1967.

Received 20 April 1970.

(Revised 7 August 1970.) 